\title{
DIAGNOSTIC CHALLENGE OF PRUNE BELLY SYNDROME: REPORT OF TWO CASES
}

\author{
Nikoleta G. TABAKOVA ${ }^{1,2} \bowtie$, Boyan D. BALEV ${ }^{3}$ \\ ${ }^{1}$ Department of Obstetrics and Gynecology, Medical University Varna, Varna, Bulgaria \\ ${ }^{2}$ Obstetrics and Gynaecology Hospital SBAGAL Varna, Varna, Bulgaria \\ ${ }^{3}$ Department of Diagnostics Imaging and Radiotherapy, Faculty of Medicine, St Marina University \\ Hospital, Medical University of Varna, Bulgaria
}

Received 08 Aug 2021, Accepted 30 Aug 2021
htrps://doi.org/10.31688/ABMU.2021.56.3.12

\begin{abstract}
Introduction. Prune belly syndrome is a rare congenital malformation, which sets some diagnostic challenges especially in the first trimester of pregnancy.

Case presentation. We describe two cases of prune belly syndrome, accurately diagnosed in the first trimester with the use of ultrasound. The patients had no risk factors and no genetic or congenital anomalies in their families. The early diagnosis allowed the patients to interrupt the pregnancy with no long-term consequences.

Conclusions. Timely diagnosing and managing of foetal congenital defects is essential for the long-term sequels of pregnant women and their future reproductive plans.
\end{abstract}

Keywords: prune belly syndrome, urinary tract abnormalities, prenatal ultrasound.

\section{RÉSUMÉ}

Défi diagnostique du syndrome du ventre en pruneau: à propos de deux cas

Introduction. Le syndrome du ventre en pruneau est une malformation congénitale rare qui pose des problèmes de diagnostic, en particulier au cours du premier trimestre de la grossesse.

Présentation du cas. Nous décrivons deux cas de syndrome du ventre un pruneau, diagnostiqués avec précision au premier trimestre grâce à l'échographie. Les patients n'avaient aucun facteur de risque et aucune anomalie génétique ou congénitale dans leur famille. Le diagnostic précoce a permis aux patientes d'interrompre la grossesse sans inquiétude à long terme.

Conclusion. La gestion en temps opportun des malformations congénitales fotales est essentielle pour les séquelles à long terme des femmes enceintes et leurs futurs plans de reproduction.

Mots-clés: syndrome du ventre en pruneau, anomalies des voies urinaires, échographie prénatale. 


\section{INTRODUCTION}

Prune belly syndrome (PBS), also known as Eagle Barrett syndrome, is a rare congenital anomaly of unknown aetiology. First described by Frölich in 1839, PBS affects predominantly male foetuses, with an estimated prevalence of ${ }_{1}$ in $35,000-50,000$ live births ${ }^{1-3}$. Some studies have suggested a genetic inheritance and association with trisomy 13 and $18^{4,5}$. It consists of a triad of genitourinary tract abnormalities, anterior abdominal wall distension and musculoskeletal anomalies ${ }^{6}$. Urinary tract abnormalities which define the PBS vary in severity and clinical presentation, and often include bilateral hydroureteronephrosis with extremely dilated, tortuous ureters, renal dysplasia, enlarged urinary bladder and dilated posterior urethra without urethral obstruction ${ }^{7,8}$. An association with other gastrointestinal, respiratory, and cardiovascular anomalies was found ${ }^{9}$. There are few reports in the literature regarding the first-trimester ultrasound diagnosis of $\mathrm{PBS}^{10}$. We present two cases of an early-diagnosed PBS during the first trimester, highlighting the importance of prenatal ultrasound evaluation for early detection and timely management of the syndrome.

\section{Case presentation}

We present the case of a 24-year-old primigravida at 13 weeks of gestation, who was referred to a specialist for an early scan between $11 w 0 d$ and $13 \mathrm{w} 6 \mathrm{~d}$. The woman had no previous history of illness or surgical interventions. The pregnant woman and her husband did not report to have any genetic or congenital anomalies in both their families. Her current pregnancy was spontaneous, with no history of drugs, tabaco or alcohol abuse. The early scan diagnosis revealed a foetus with severe urogenital tract abnormalities, defined as prune belly syndrome (Fig. $1,2)$. The patient presented to our hospital for second opinion. The ultrasonographic specialists performed another foetal morphology scan, and the diagnosis was confirmed. The ultrasound diagnosis was based on the findings of an abnormally dilatated bladder with thick wall $(5 \mathrm{~mm})$, absence of posterior urethral valves, hydroureters and bilateral hydronephrosis, as well as distention of the abdominal wall. We counselled the couple and they opted for pregnancy termination because of the poor foetal prognosis. Written informed consent was obtained for the procedure and we performed elective pregnancy termination with the use of the combined method-misoprostol vaginal tablets for cervical ripening and dilatation, till expulsion of the foetal parts and subsequent curettage. The patient was discharged two days after the procedure,

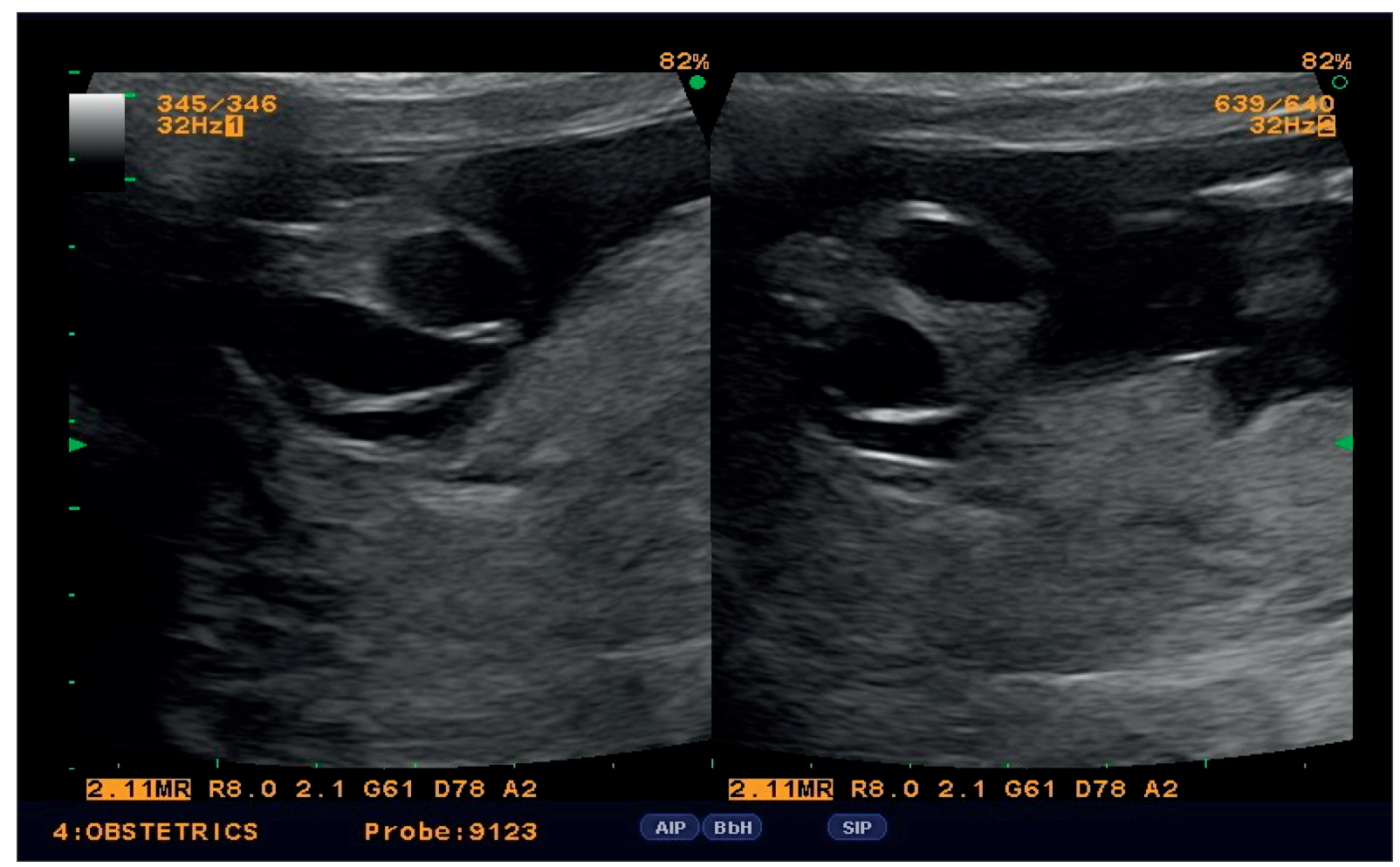

Fig. 1. Transvaginal ultrasonography. Foetus at 13 w2d with prune belly syndrome - dilatated ureters. 


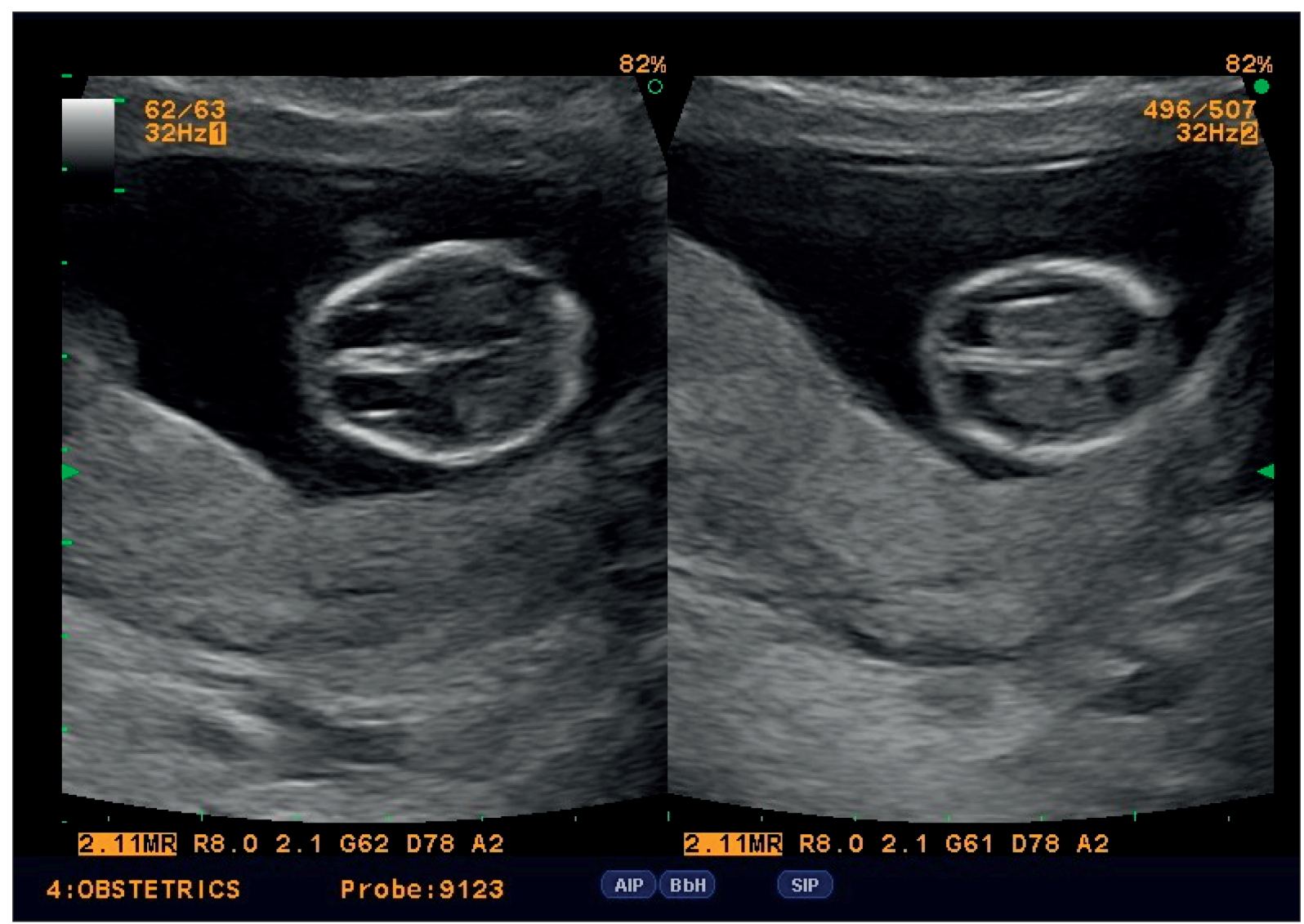

Fig. 2. Transvaginal ultrasonography. Plexus choroideus and falx cerebri of a foetus with prune belly syndrome.

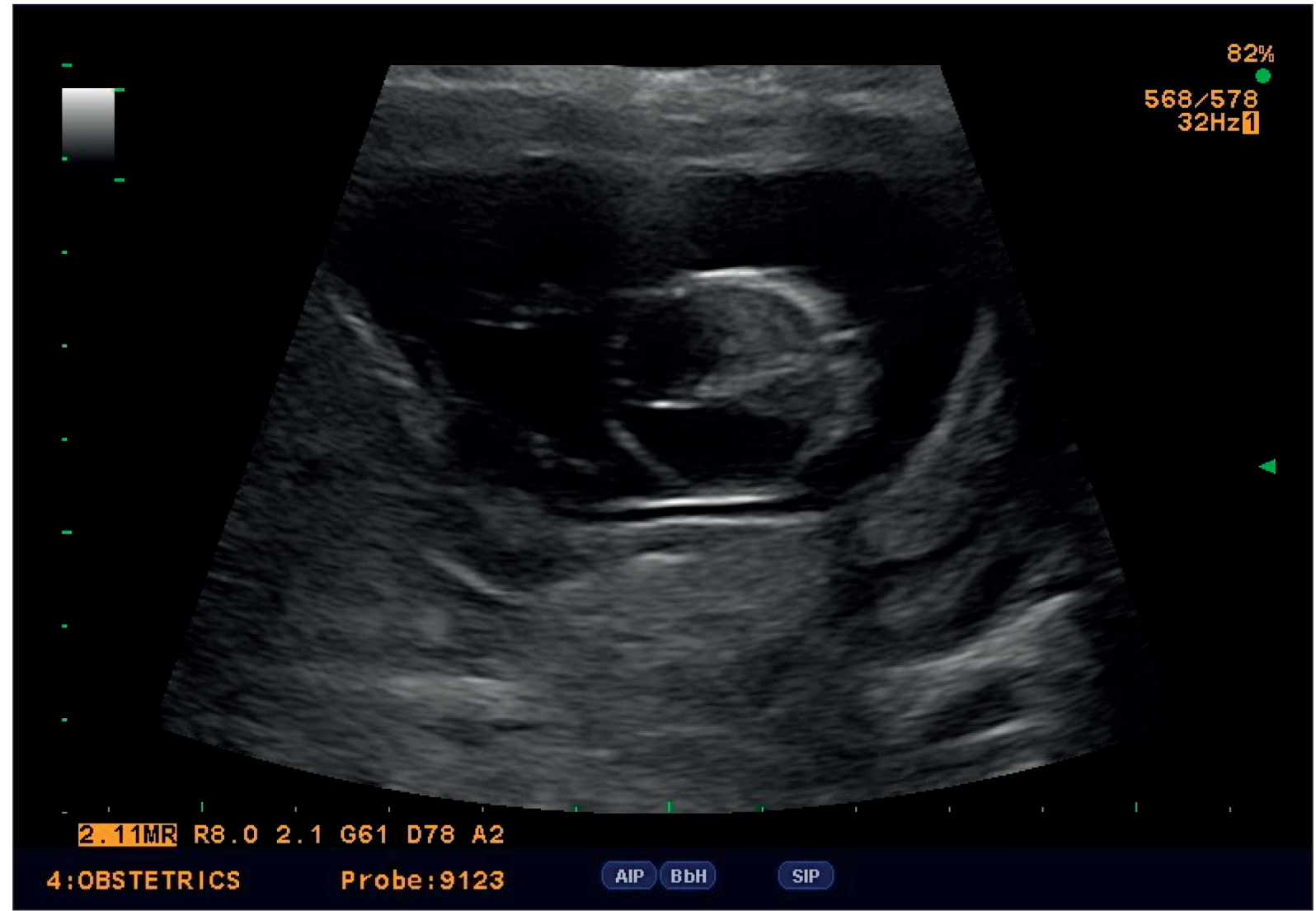

Fig. 3. Transvaginal ultrasonography. Foetus at 13 w2d with prune belly syndrome - anterior abdominal wall distension. 


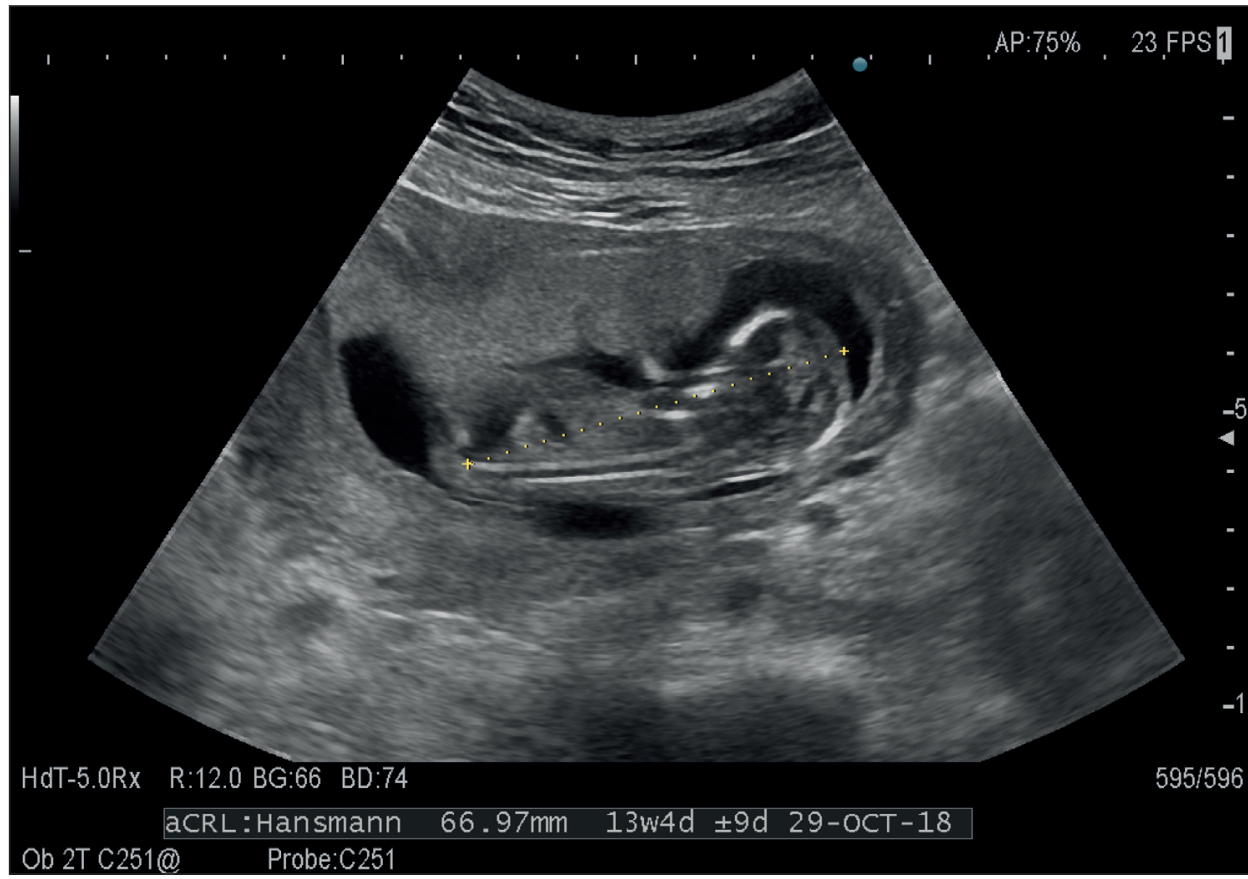

Fig. 4. Ultrasonography. Crown-rump length of a foetus at 13w4d with prune belly syndrome.

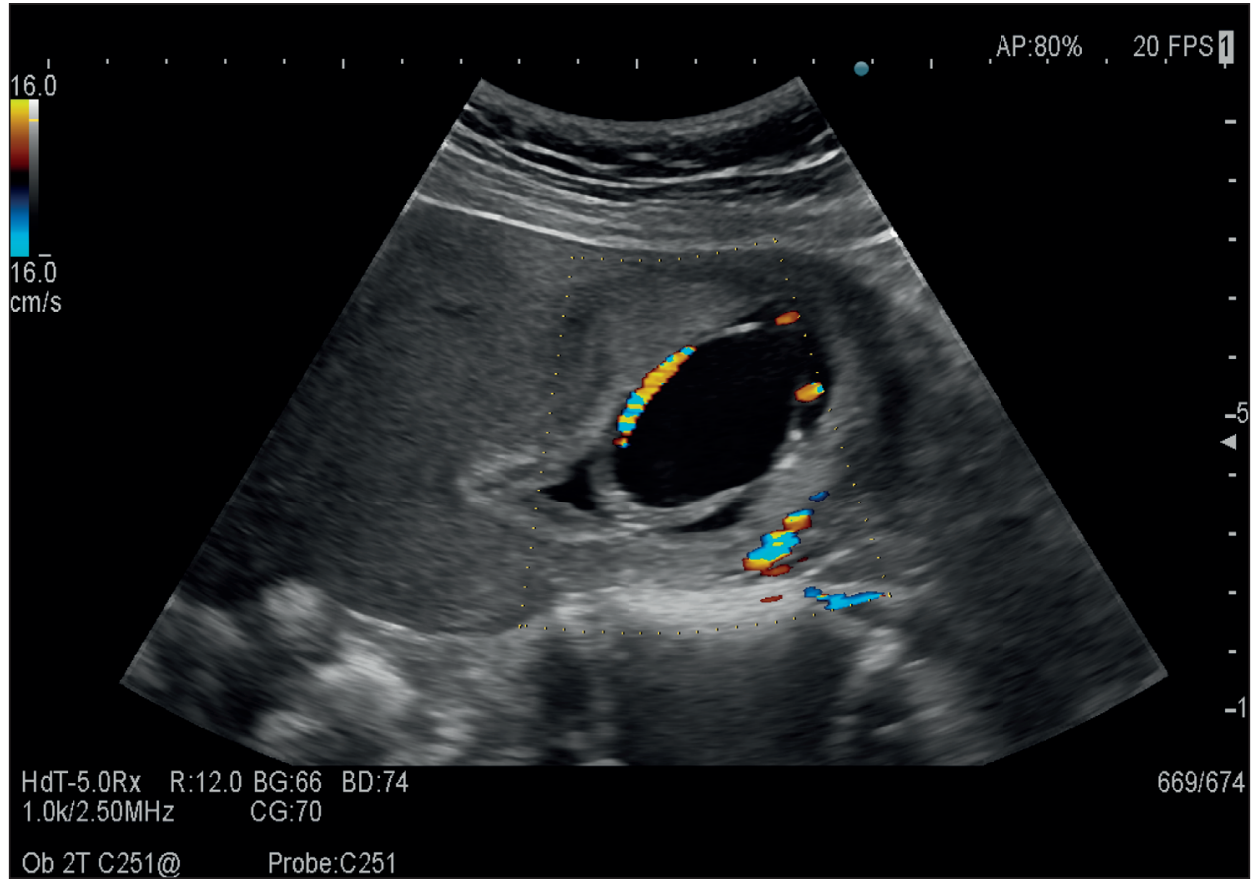

Fig. 5. Ultrasonography. Dilatated bladder and umbilical arteries of a foetus with prune belly syndrome.

without complications. A written informed consent was obtained from the patient to publish her case.

The second case was a 39-year-old multiparous woman who was referred to our hospital for bleeding in the first trimester. The patient had two previous pregnancies and two normal deliveries. She did not report any risk factors, excepting her advanced age. The ultrasound at admission revealed some severe genitourinary tract abnormalities of the foetus, described first as megacystis. A detailed first trimester ultrasound was performed to evaluate the foetal malformation. The diagnosis was a congenital anomaly of the foetus (PBS), due to the absence of posterior urethral valves, which are present in megacystis (Fig. 4-7). The absence of posterior urethral valves, known as key-hole sing, is used as a marker for differentiation between the two similar 


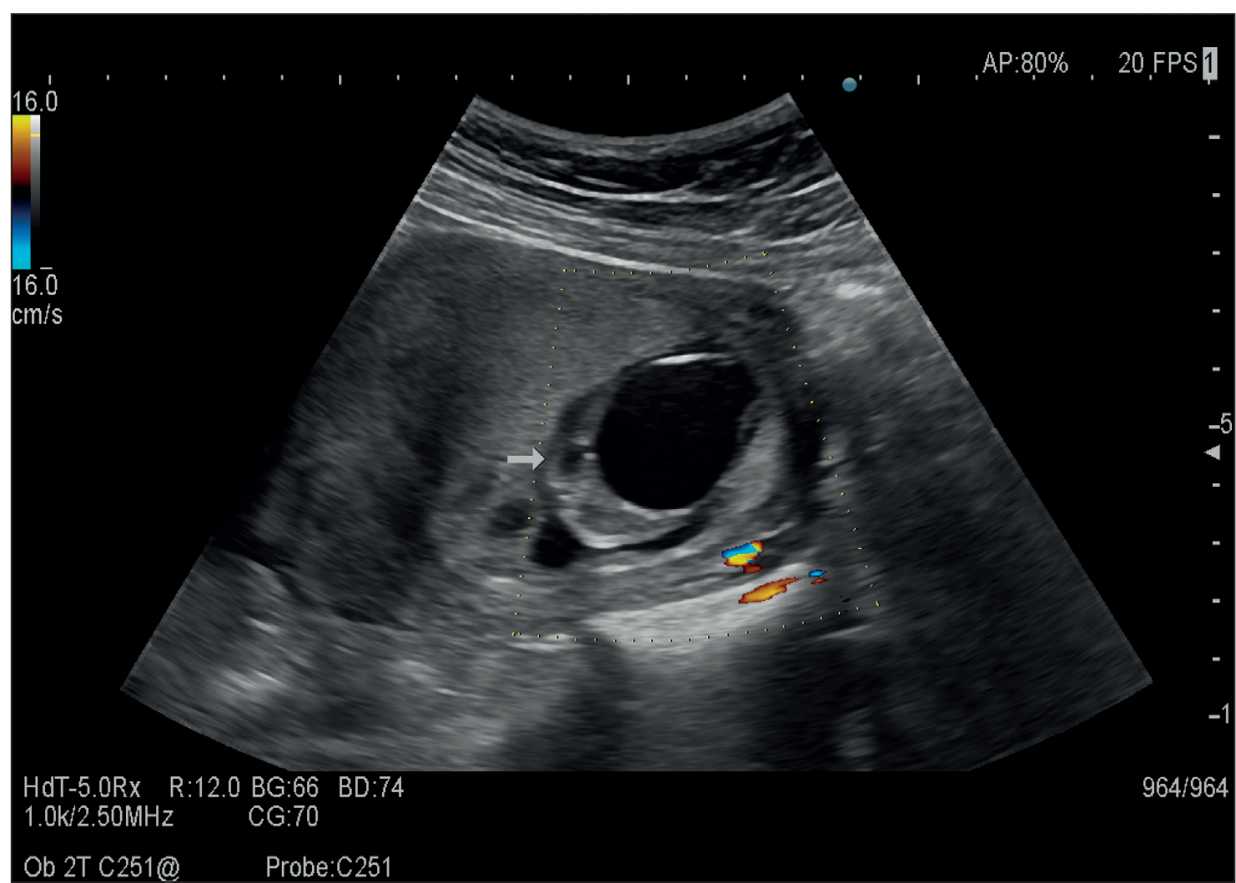

Fig. 6. Ultrasonography. Key-hole sign suggesting the absence of posterior urethral valves of a foetus with prune belly syndrome.

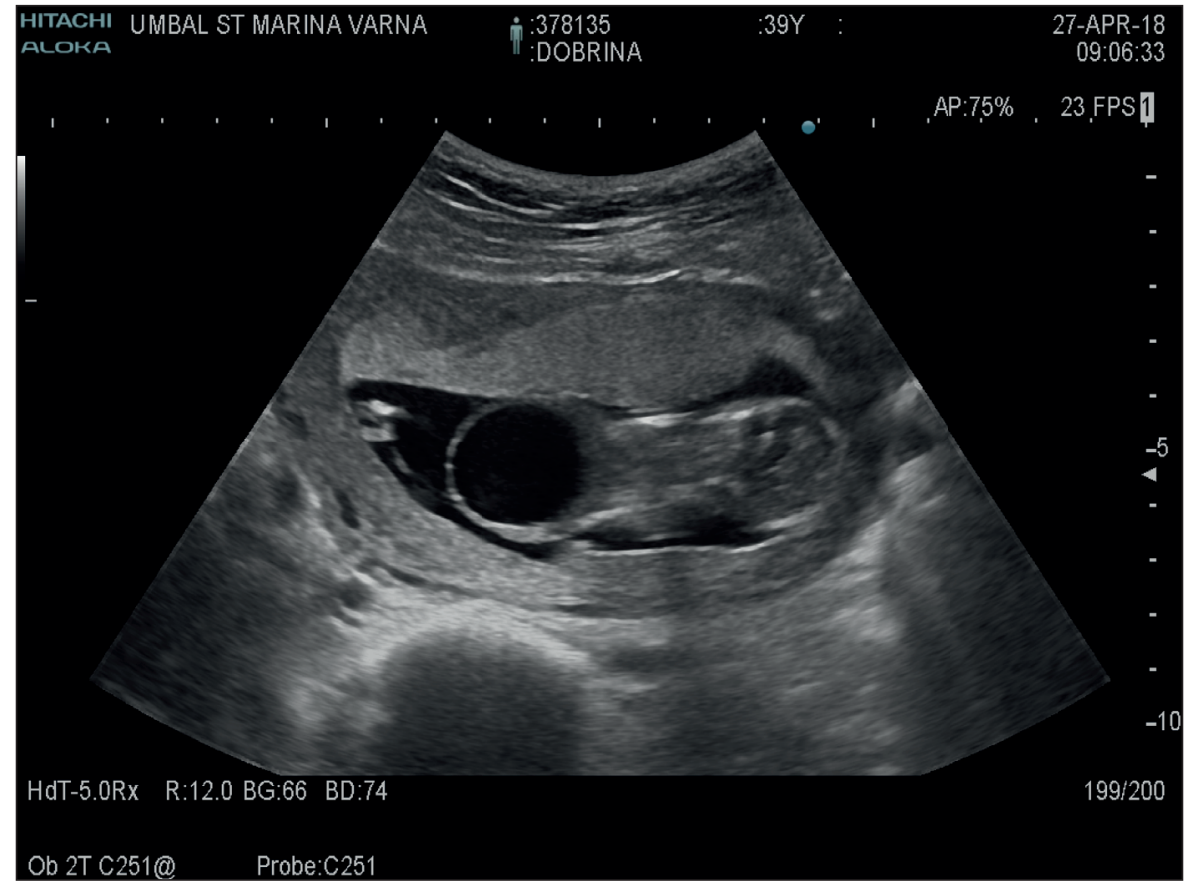

Fig. 7. Ultrasonography. Distended urinary bladder wall and distended abdominal wall of the foetus with prune belly syndrome.

urogenital tract abnormalities - prune belly syndrome and megacystis. Detailed information of the foetal condition was given to the patient, and she decided to terminate the pregnancy. We performed the termination with the combined method, as in the previous case, after written informed consent of the patient. Patient was discharged two days after the procedure, without complications. A written informed consent was obtained from the patient to publish her case.

\section{Discussion}

We presented two cases of prenatal-diagnosed PBS, early during the first trimester. The pregnant 
women decided to interrupt their pregnancies because of the poor prognosis of PBS.

We conducted a detailed literature search and found that most of the cases of PBS are diagnosed after birth and very few in the prenatal period. Some case reports of the prenatal-diagnosed cases concluded that the detection of the syndrome is possible during the early ultrasound scan between 11 and 13 gestational weeks if abnormalities of the urinary tract and abdominal wall are present at that time $e^{8,10,11}$.

Prune belly syndrome is defined as a spectrum of features, some of which could be recognized from a well-experienced sonographer during early foetal scan. The early prenatal diagnosis of PBS is challenging due to the difficulties in differentiating the condition from megacystis. Any uncertainties could have serious sequel regarding the decision of the parents for induced abortion in cases with PBS, while a case of megacystis could be easily managed with surgery and has good prognosis. The key for the differential diagnosis between the two conditions is the key-hole sign, which represents the absence of posterior urethral valves in cases with PBS and is detected by ultrasound.

PBS is a rare congenital malformation with poor prognosis, dependent on the severity of lung hypoplasia and on long-term on the severity of renal abnormalities ${ }^{13}$. The most severe form is characterized by progressive distension leading to oligohydramnios, pulmonary hypoplasia, and possible stillbirth ${ }^{14}$. In Bulgaria the law allows procedures for termination of pregnancy in some prenatal-diagnosed malformations of the foetus with poor prognosis after birth or with severe long-term consequences. A medical advisory commission discusses each case and allows termination of pregnancy in severe congenital, chromosomal, or genetic abnormalities if the parents desire.

\section{Conclusions}

The prenatal ultrasound detection of congenital malformations allows women to make their informed consent for induced abortion in cases of severe foetal abnormalities with poor prognosis and survival rate. The two presented cases of prune belly syndrome diagnosed early during the first trimester highlight the possibility of an early detection of severe urinary tract abnormalities by experienced sonographers.

\section{Author Contributions:}

N.T. was responsible for the treatment procedure including induced abortion. B.B. performed the ultrasound diagnosis in both cases. N.T. wrote the manuscript and translated the abstract in French. All authors have read and agreed to the published version of the manuscript.

\section{Compliance with Ethics Requirements:}

"The authors have no conflict of interest relevant to this article"

"The authors declare that all the procedures and experiments of this study respect the ethical standards in the Helsinki Declaration of 1975, as revised in 2008, as well as the national law. Informed consent was obtained from the patients included in the study"

"No funding for this study"

\section{Acknowledgments}

None

\section{References}

1. Frölich F. Der Mangel der Muskeln, insbesondere der Seitenbauchmuskeln. Würzburg: Dissertation; 1839.

2. Routh JC, Huang L, Retik AB, Nelson CP. Contemporary epidemiology and characterization of newborn males with prune belly syndrome. Urology 2010; 76(1):44-48.

3. Reinberg Y, Shapiro E, Manivel JC, Manley CB, Pettinato G, Gonzalez R. Prune belly syndrome in females: a triad of abdominal musculature deficiency and anomalies of the urinary and genital systems. J Pediatr 1991;118(3):395-398.

4. Baird PA, MacDonald EC. An epidemiologic study of congenital malformations of the anterior abdominal wall in more than half a million consecutive live births. Am J Hum Genet 1981;33(3):470-478.

5. Ramasamy R, Haviland M, Woodard JR, Barone JG. Patterns of inheritance in familial prune belly syndrome. Urology. 2005;65(6):1227.

6. Eagle JF Jr, Barrett GS. Congenital deficiency of abdominal musculature with associated genitourinary abnormalities: A syndrome. Report of 9 cases. Pediatrics 1950;6(5):721-736

7. Tagore KR, Ramineni AK, Vijaya Lakshmi ARNB. Prune belly syndrome. Case Rep Pediatr. 2011;2011:121736.

8. Tonni G, Ida V, Alessandro V, Bonasoni MP. Prune-belly syndrome: case series and review of the literature regarding early prenatal diagnosis, epidemiology, genetic factors, treatment, and prognosis. Fetal Pediatr Pathol 2012;31(1):13-24.

9. Zugor V, Schott GE, Labanaris AP. The Prune Belly syndrome: urological aspects and long-term outcomes of a rare disease. Pediatr Rep 2012;4(2):e20.

10. Yamamoto H, Nishikawa S, Hayashi T, Sagae S, Kudo R. Antenatal diagnosis of prune belly syndrome at 11 weeks of gestation. J Obstet Gynaecol Res. 2001;27:37-40.

11. Hoshino T, Ihara Y, Shirane H, Ota T. Prenatal diagnosis of prune belly syndrome at 12 weeks of pregnancy: case report and review of the literature. Ultrasound Obstet Gynecol. 1998;12:362-366.

12. Papantoniou N, Papoutsis D, Daskalakis G, et al. Prenatal diagnosis of prune-belly syndrome at 13 weeks of gestation: case report and review of literature. J Matern Fetal Neonatal Med. 2010;23:1263-1267.

13. Xu W, Wu H, Wang DX, Mu ZH. A case of prune belly syndrome. Pediatr Neonatol. 2015;56(3):193-6.

14. Woodard JR, Trulock TS. Prune belly syndrome. In Walsh PC, Gittes RF, Perlmutter AD, Stamey TA, eds. Campbell's Urology. Philadelphia: WB Saunders, 1986:2159-78. 